\title{
Exploring the consequences of person-environment misfit in the workplace: A qualitative study
}

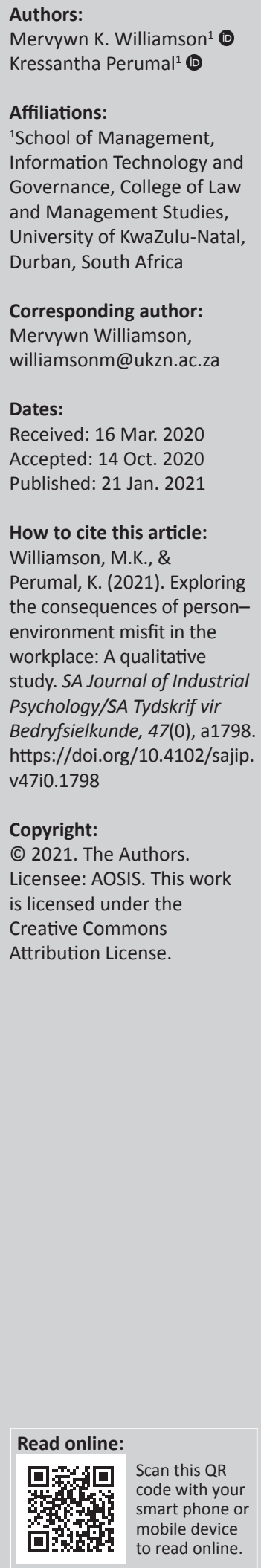

Orientation: Although the literature on person-environment fit has burgeoned, misfit has been relatively overlooked. The 21st-century business environment has seen an increase in the number of employee misfits in the workplace, and this has proved a challenge to many organisations. It is uncertain how misfit impacts on employees and organisations experiencing this phenomenon.

Research purpose: The purpose of this study was to broaden the current misfit research boundaries by exploring the consequences of misfit as experienced by individuals at work.

Motivation for the study: There exist several under-researched areas in the misfit terrain. One such is the effect of misfit in the workplace. This study aimed to fill this void.

Research approach, design and method: A qualitative constructivist grounded theory approach was adopted. Using purposive and snowball sampling, 40 employee misfits participated in face-to-face, semi-structured, in-depth interviews. Interviews were transcribed verbatim and data analysed by using four steps prescribed by grounded theory researchers.

Main findings: Results highlight two themes that epitomise the consequences of misfit: (1) causing negative reactions in individual employees and (2) producing organisationally directed detrimental outcomes.

Practical/managerial implications: The study provides managers with a more profound understanding of the adverse consequences of misfit in the workplace and this will assist them in dealing more effectively with misfits.

Contributions/value added: This research contributes to the literature in two ways: (1) it contributes to the theory of misfit by adding to the conception that misfit is a qualitatively different construct to that of low fit or the absence of fit, and (2) our approach sheds light on the multifaceted and intricate construct of misfit and its consequences.

Keywords: misfit; person-environment misfit; person-environment fit; constructivist grounded theory; qualitative research.

\section{Introduction}

\section{Orientation}

There exists a large body of research examining the construct of person-environment (PE) fit (Andela \& Van der Doef, 2019; Oh et al., 2014). Broadly, PE fit has been defined as the 'compatibility between an individual and a work environment that occurs when their characteristics are well matched' (Kristof-Brown, Zimmerman, \& Johnson, 2005, p. 281). Past research has suggested that PE fit could be linked to a range of beneficial, individual and organisational outcomes. For example, studies have demonstrated that people who share similar values, personality or other characteristics with their organisational environment or people in it are more satisfied and committed to their jobs (Park, Oh, \& Lee, 2018; Silverthorne, 2004). Person-environment fit has also been shown to be positively associated with job performance (Kristof-Brown et al., 2005) and inversely related to stress and job burnout (Edwards \& Cooper, 1990; Siegall \& McDonald, 2004). Research has revealed that PE fit is a sought-after construct and that organisations should recruit and select new employees on the basis of fit (Barrick \& Parks-Leduc, 2019).

Although the literature on PE fit has proliferated, PE misfit or misfit has been relatively ignored (Cooper-Thomas \& Wright, 2013). The dynamics of the contemporary business environment has witnessed an increase in the prevalence of misfits in the workplace (Vogel, Rodell, \& Lynch, 2016). These misfits have proved to be a challenge for many organisations. In general terms, misfit denotes a lack of fit in which the characteristics of 
the person $(\mathrm{P})$ are not equal to that of the environment (E) (Harrison, 2007). Follmer, Talbot, Kristof-Brown, Astrove and Billsberry (2018, pp. 440-441) define misfit as 'the negative end of the fit continuum, and is associated with discomfort or incompatibility'. According to Vleugels, Tierens, Billsberry, Verbruggen and De Cooman (2019), misfit is a negative, unwanted, unpleasant and undesirable condition, which is extremely incapacitating and damaging. Misfit has also been likened to an 'organisational psychopathology' - an enduring and negative state of mind (Billsberry, 2008, p. 2). Scholars have also stated that misfit and fit are not dichotomous constructs and that misfit should be conceived as qualitatively distinct (Kristof-Brown \& Guay, 2011; Talbot \& Billsberry, 2010). This raises a number of questions about which conception of misfit is authentic and pertinent in providing an accurate picture of the construct, its antecedents and outcomes.

Researchers have suggested that more qualitative research is needed to satisfactorily capture individuals' experiences of being a misfit in the workplace (Follmer et al., 2018; Talbot \& Billsberry, 2010). There is a considered argument that refutes the equivalence of low levels of fit, absence of fit and misfit. It has been asserted that misfit is a much more composite construct and that the experience is markedly worse and debilitating (Hollyoak, Talbot, Pyper, \& Billsberry, 2017; Vleugels et al., 2019). Thus, misfit may not be triggered by the same factors or elicit the same consequences as that of low fit or the absence of fit (De Cooman, Mol, Billsberry, Boon, \& Den Hartog, 2019). In this study, we conceptualised misfit as a qualitatively distinct construct from that of low fit or the absence of fit (derived quantitatively through P-E difference scores), where employees' experiences were solicited through face-to-face, semi-structured, in-depth interviews.

Previous research into misfit has been restricted to a few areas. Scholars have explored the similarities and differences between fit and misfit (e.g. Talbot \& Billsberry, 2007), shed light on misfit as a psychological construct (e.g. Hollyoak, 2016), examined the antecedents of misfit (e.g. CooperThomas \& Wright, 2013) and investigated how individuals mitigate and cope with misfit in the workplace (e.g. David et al., 2019; Hewlin, Dumas, \& Burnett, 2017). Past research examining the effects or consequences of misfit has operationalised it as low fit, calculated differences between $\mathrm{P}$ and $\mathrm{E}$ or perceived misfit by using Likert-type measuring instruments. These studies have linked misfit to increased stress levels, low job satisfaction and performance (Deng, Wu, Leung, \& Guan, 2016; Jansen \& Kristof-Brown, 2005; Trautmann, Voelcker-Rehage, \& Godde, 2011). Whilst these studies have generally shown misfit in a negative light, there remains much conjecture with regard to the actual consequences of misfit. As highlighted earlier, low fit, the absence of fit or misfit may not produce the same outcomes. Perhaps, exploring the consequences of misfit from real experiences of individuals may unearth new information that could elucidate this heretofore under-researched and grey area. This study sought to address this gap in the literature.

\section{Research purpose and objective}

The purpose of this study was to broaden the current misfit research boundaries by investigating the impact of misfit as experienced by individuals in the workplace. To achieve this, we adopt a constructivist, qualitative grounded theory approach by using face-to-face, semi-structured, in-depth interviews on a diverse group of employee misfits. These individuals are well positioned to reveal their authentic experiences about how misfit has affected them personally, other people in their workplaces and their organisations. Thus, the objective of this research was to explore the consequences of misfit in the workplace.

This study is timely as it sought to answer the call for more research into misfit to enrich our understanding of this highly complex and multifaceted construct and its consequences. This research contributes to the literature in two ways. Firstly, we contribute to the theory of misfit by adding to the conception of misfit being a qualitatively different construct to that of low fit or the absence of fit. Secondly, our approach sheds light on the multifaceted and intricate nature of misfit and its consequences.

\section{Literature review}

\section{Understanding misfit}

In one of the most extensively used frameworks in PE fit research, the attraction-selection-attrition (ASA) framework, Schneider (1987) submitted that individuals are attracted to organisations and selected by them when their values match or are similar. Moreover, these individuals are retained by these organisations when, over time, there is no deviance in value similarity. This inculcates acceptable levels of PE fit and concomitant positive work outcomes. However, it could also lead to an increase in homogeneity and a lack of diversity in organisations. The ASA framework also speculates that not all individuals are retained by these organisations (Schneider, 1987). Over time, some individuals discover that they 'do not fit in' or misfit with the values or other characteristics of the organisation or people within them. These individuals, who do not fit in, are inclined to leave the organisation. However, scholars have questioned whether all these individuals, who misfit, instantaneously exit their organisations (Wheeler, Buckley, Halbesleben, Brouer, \& Ferris, 2005; Wheeler, Gallagher, Brouer, \& Sablynski, 2007). Leaving the organisation might not be a prudent decision in tight labour markets where unemployment is excessively high. Billsberry, Ambrosini, Marsh, Moss-Jones and Van Meurs (2005, p. 12) have claimed that individuals who misfit are not always persuaded into exiting their organisations; nevertheless, they persist by 'acting as centres of rebellion, disaffection, and malcontent in order to express feelings of stress, dissatisfaction and frustration'. These assertions suggest that misfit may have deleterious consequences for those individuals who have opted to remain. 
Prior research and scholarly writings have focussed on how those who remain in organisations cope with misfit. Wheeler et al. (2005) suggested a number of possibilities to consider such as adaptation, inaction, voice or impression management before leaving the organisation. If successful, some of these options could prolong the stay of misfits and, in some cases, experience a turnaround in their status or to become productive misfits. Doblhofer et al. (2019) focussed on dealing with the negative effects of value incongruence, a type of misfit, through the use of three coping strategies: positive reframing, facades of conformity and self-disclosure. These strategies were found to diminish the effects on outcomes such as absenteeism and affective commitment. Vogel et al. (2016) empirically examined the role of job crafting and employees' leisure activity in alleviating the negative impact of value incongruence on specific work outcomes. These proactive behaviours were shown to be significant in reducing value incongruence's negative effect on employee engagement and job performance.

The question of what people do in response to misfit was further explored by Follmer et al. (2018) in their qualitative study, by using interviews, on a diverse sample of employee misfits. Three wide-ranging reactions to the experience of misfit were presented, namely, resolution, relief and resignation. These findings offer hope to employees who experience misfit to seek alternatives to deal with their condition before opting for voluntary exit or mandatory termination of employment by their organisations. Hewlin et al. (2017, p. 178) noted that employees frequently react to their value incongruence by 'pretending to fit in'. They described these behaviours as facades of conformity deceitful images, depictions or demonstrations displayed by employees to create a false impression that they endorse the values of the organisation or members within it.

Edwards (2008) has noted the dearth of theory in the PE fit literature that could be used to assist us in our understanding of the PE fit construct. This same observation could be applied to the area of misfit. Wheeler, Halbesleben and Shanine (2013) proposed the use of the conservation of resources (COR) theory as an appropriate theoretical lens to help us understand the consequences of misfit. Conservation of resources theory claims that individuals have a desire to acquire, safeguard and increase their resources through the process of resource investment. When there is a genuine loss of resources, individuals will respond by being stressed out (Hobfoll, 1989). Resources in this context pertain to a wide range of factors that are regarded by individuals as important in attaining their goals, such as, values, working conditions, finances and individual characteristics. Wheeler et al. (2013) contend that employees recognise their misfit through an assessment of their resource situation at work. For example, if these employees discover that they do not have the necessary resources to satisfy the demands in their workplaces that are in line with their personality, values or other characteristics, the outcome of the assessment will be negative. This may result in further resource depletion and eventually a resource loss spiral, which is complemented by a number of harmful outcomes such as high levels of stress and burnout and increased turnover (Wheeler et al., 2013).

\section{The effects of misfit}

There is quantitative evidence to show that misfit is associated with a range of negative outcomes. This line of research has examined the effects of misfit by using different conceptualisations and operationalisations of the construct. For example, value incongruence, a type of misfit, was shown to increase stress and burnout (Bocchino, Hartman, \& Foley, 2003; Bouckenooghe, Buelens, Fontaine, \& Vanderheyden, 2005). Value incongruence was assessed by using difference scores between $\mathrm{P}$ and $\mathrm{E}$ or Likert-type measuring instruments where respondents were required to indicate their agreement to a series of statements relating to their values and that of their organisations. Using a similar methodology, Bao, Vedina, Moodie and Dolan (2013) found various types of value incongruence having distinctive effects on burnout, turnover intentions and inclinations for accidents at work in a sample of nurses. This finding suggests that different types of value incongruence may perhaps reveal different consequences.

The influence of misfit in increasing actual employee turnover or intentions to leave the organisation was found to be much more intricate and convoluted than a simple linear relationship. Shedding light on this, Wheeler et al. (2007) reported that employees, who misfit with their organisations, will intend leaving only when there is an existence of other prospects of employment for them. Moreover, job satisfaction was shown to mediate the relationship between misfit and intent to turnover. Here, participants were required to indicate how well their values match or fit the values of their organisations on a three-item perceived fit scale.

Supplies-values misfit was associated with an increase in somatic complaints and depression (Shaw \& Gupta, 2004). It was conceptualised as the mismatch between a preferred level of a specific task characteristic (values) and the level of this characteristic provided by the job (supplies) that the individual occupied. This type of misfit was also assessed by using difference scores and polynomial regression to test its effects. Cools, Van den Broeck and Bouckenooghe (2009) examined the effects of cognitive misfit - conceptualised as the incongruence between cognitive styles of individuals and prevailing organisational climate - on job satisfaction, job search behaviour and intention to leave the organisation. The hypothesised effects did not materialise; however, individuals who displayed higher creating styles than normal showed increasing job search behaviours and intentions to leave the organisation. Liu, Luksyte, Zhou, Shi and Wang (2015) demonstrated that employees' perceptions of their overqualification, a form of person-job misfit, increased their levels of counterproductive work behaviours (CWBs) in their organisations. In this study, person-job misfit was measured by using a nine-item perception of over-qualification scale where employees had to state their agreement or 
disagreement to a series of questions on a Likert-type scale. Using polynomial regression, Bermiss and McDonald (2018) examined individuals' political ideological misfit and its impact on the prospect of them leaving their organisations. Individuals who exhibited conservative misfit, that is, when their political beliefs are more conservative than their organisations, were more likely to leave than liberal misfits.

Research thus far suggests that there are several conceptions and operationalisations associated with misfit and its effects have been investigated in predominantly quantitative studies. Whilst these studies have merit and contributed to our understanding of misfit consequences, they may not have satisfactorily captured the genuine impact of this construct as experienced by individuals in the workplace.

\section{Research design \\ Research approach and strategy}

This research was located in the constructivist paradigm. Constructivists refute the existence of an objective reality and subscribe to the view that realities are social constructions of the mind (Guba \& Lincoln, 1989). These are highly subjective and can vary according to the individual concerned. Moreover, from an epistemological perspective, constructivists emphasise 'the subjective interrelationship between the researcher and participant, and the construction of meaning' (Mills, Bonner, \& Francis, 2006, p. 2). Generally, scholars who position themselves within this paradigm have a proclivity towards the use of qualitative data collection methods such as interviews or focus groups (Creswell \& Poth, 2018). These methods elicit rich data that allow researchers to 'reflect on subjective meanings and interpretations, the social and culturally embedded nature of individual experiences; and the relationship between the researcher and the researched' (Broom \& Willis, 2007, p. 25).

A qualitative, constructivist grounded theory approach was used in this study. Grounded theory methodology comprises orderly, inductive, consistent and fair approaches to undertaking investigations with the primary objective of contributing to theory (Bryant \& Charmaz, 2007). The constructivist approach to grounded theory recognises that the study data and analyses are shaped from the collective experiences of participants and researchers (Charmaz, 2006). Misfit is an area that has been underresearched and lacks sound theory to underpin further scholarly inquiry (Edwards, 2008; Wheeler et al., 2013). The use of the constructivist grounded theory approach to investigate the consequences of misfit in the workplace fits perfectly with its stated goals of emphasising new discoveries or offering new perspectives where there is a paucity of knowledge on a particular phenomenon. The adoption of a constructivist approach was based on the conviction that neither the researchers nor the participants arrived at this study untouched by the world.

\section{Research method}

\section{Research setting}

The research was undertaken on employee misfits who worked for organisations that represented a broad range of business sectors in the province of KwaZulu-Natal, South Africa. The interviews were conducted in various secured locations: offices of participants, boardrooms and offices at the researchers' academic institution. In all these locations, participants' privacy was safeguarded.

\section{Entrée and establishing researcher roles}

All interviews were conducted and audio-recorded by one person, namely the first author. This was to ensure consistency and the development of trust amongst participants. Because of the sensitive, emotional and personalised nature of misfit, the researchers treaded carefully when approaching potential participants. This task was also undertaken by the first author whose responsibility was to handle all communication with the respondents. Details of how participants were approached and selected are discussed under the research participants and sampling methods section below. Individuals agreed to participate in their individual capacity and signed informed consent forms.

\section{Research participants and sampling methods}

To qualify, potential participants were required to fulfil the following criteria: (1) be currently or previously employed for more than a year in an organisation and (2) should have experienced misfit in that particular organisation. These pre-set criteria for participant eligibility were necessary to obtain rich and high-quality data from participants who had actually experienced misfit in their workplaces. Setting a baseline of a minimum of 1 year's work experience was an essential requirement as it was considered unlikely that employees with less than a year's experience would be in a position to speak confidently about organisational matters associated with misfit.

This study followed a two-stage sampling approach. The first stage employed purposive sampling, which has been described as apposite when choosing distinctive cases that are particularly informative (Neuman, 2014). Because of the sensitivity surrounding misfit and the fact that it had traditionally been viewed in a negative light, many potential participants who had experienced misfit were reluctant to talk about it for fear of being labelled, ostracised or victimised. Thus, the recruitment of participants was an arduous task. Word of mouth was used to lobby interest in the study as was the researchers' own knowledge of acquaintances who indicated that they did not fit in with their organisations. During the recruitment of these potential participants, face-to-face meetings and telephonic conversations were held to explain the purpose and background of the study, the selection criteria, and confidentially issues and other relevant protocol. Employees, who demonstrated an interest in taking part in the study and met the selection criteria, were forwarded information about the research. 
Purposive sampling was tardy in obtaining potential participants as many were averse to revealing themselves as misfits and unwilling to be a part of the research. The second stage used snowball sampling to acquire additional participants through referral networks. Snowball sampling is often used when it is challenging to identify the relevant participants for a study (Schindler, 2019). The number of employee misfits who voluntarily participated in this study totalled 40. The make-up of the sample included 24 (60\%) female participants and $16(40 \%)$ male participants. There was a broad representation of different age groups with the youngest being 22 years old and the oldest at 68 years. The major race groups were included; Indians were in the majority $(50 \%)$, followed by black people $(35 \%)$, white people $(10 \%)$ and mixed races $(5 \%)$. Participants demonstrated a wide range of work experience with a minimum of 1 year and a maximum of 33 years (average tenure equalled 7 years). There were a number of industry sectors represented: marketing, sales and retail (33\%), financial services $(28 \%)$, education $(20 \%)$, logistics or supply chain $(5 \%)$, medical or pharmaceutical $(5 \%)$, parastatals or government $(5 \%)$, research $(2 \%)$ and, tourism and hotel $(2 \%)$.

\section{Data collection method}

Face-to-face, semi-structured, in-depth interviews were used to collect data from participants. This method permitted the interviewer to probe intensely into matters of a private and public nature. In-depth interviews have been known for their flexibility and interactive nature, where participants are free to relate their stories and experiences in a non-hostile environment and without any constraints (Yeo et al., 2014). Guided by an interview schedule, the researchers asked participants a number of pertinent questions regarding their conceptions and experiences of misfit, and how it impacted their organisations and them personally. Participants' narrations offered a gateway to a more profound comprehension of how misfit affects employees and organisations alike.

Dates and venues for the interviews were agreed upon in advance with each of the participants. Reminders were sent out a few weeks before interviews took place to ensure prompt attendance. All interviews were held in safe locations and free of interferences. Participants were forthright when describing their experiences and provided novel insight into misfit and its consequences. The duration of the interviews varied between $45 \mathrm{~min}$ and $90 \mathrm{~min}$.

\section{Data recording}

All interviews were audio-recorded by using a dictaphone. Permission to audio record was sought and received from all participants before their interviews. Careful attention was paid to ensure that the recordings were free of any noise or interferences that could have emanated from the offices or boardrooms and surroundings where the interviews were held. All interview recordings were transcribed verbatim on a word document by the researchers and corroborated by them and one other senior academic experienced in qualitative data analysis.

\section{Strategies employed to ensure data quality and integrity}

\section{Establishing trustworthiness}

Lincoln and Guba (1985) provide several criteria for establishing trustworthiness in a qualitative study. These include credibility, transferability, dependability and confirmability. The researchers were cognisant of this, and throughout the research process due consideration was given to addressing these criteria. For example, a detailed record of the entire research process was kept in the form of an audit trail and the independent corroboration of the interview transcripts as well as the data coding and derivation of themes or subthemes.

\section{Reflexivity}

A number of ways have been presented to ensure that reflexivity is maintained. For example, McGhee, Marland and Atkinson (2007) suggested the use of memo-writing to help researchers become cognisant of their own possible effects on the data. At the outset, the researchers acknowledged the fact that their previous experiences and knowledge of the fit or misfit area may influence their approach to the coding of the interview data. To mitigate potential bias, the researchers kept copious notes in a journal that clearly identified instances where there could have been researcher interference and what steps were taken to avoid it. At various times during the research process, the researchers undertook an introspection of themselves - this exercise would often reveal warning signals to back off from forcing their preconceived ideas during the interview process and analysis of data.

\section{Data analysis}

The interview data were analysed and coded through a process involving the following four steps that are typical of grounded theory research.

\section{Step 1: Initial open coding}

The interview transcripts were perused a number of times to obtain a thorough understanding of participants' responses and to validate accuracy and inclusiveness. Following this, and guided by the interview questionnaire, relevant responses were highlighted and open-coded. This step produced a number of open codes, which embodied a wide range of participants' responses concerning misfit and its consequences.

\section{Step 2: Refining the open coding}

A subsequent detailed examination of the initial open codes was necessary to identify any redundancies and conceptually related responses, which had been coded individually. This step further reduced the number of codes identified earlier. The outcome was the generation of a number of themes and subthemes. 


\section{Step 3: Axial coding}

A further scrutiny of the themes and subthemes was essential to ensure that these accurately represented the data. This step also included the corroboration of these themes or subthemes by the researchers and an autonomous individual who had experience in qualitative data analysis. At the end of this step, the researchers were satisfied with the coding outcomes and were confident that the themes or subthemes were an accurate reflection of the data.

\section{Step 4: Theoretical coding}

This final step entailed the consolidation of input from a review of the literature, interview data and previous coding steps to accurately depict the consequences of misfit as experienced by individuals in work context.

\section{Reporting style}

The interview data were initially coded on Microsoft word documents and then copied across to a Microsoft Excel spreadsheet where the themes and subthemes were derived. Each subtheme was supported by an array of verbatim quotations from relevant participants. In the following section, the description of the study results is structured in terms of the two major themes and constituent subthemes that emerged. Only selected excerpts attributable to specific participants were used to support the subthemes as it was not practical to include every remark made. To protect their identity and remain anonymous, all participants were allocated numbers (e.g. Participant 1 [P1], Participant 2 [P2], etc.). All interviews were conducted in English and thus averted the need for translation.

\section{Ethical consideration}

Ethical permission for this study was obtained from the Human and Social Sciences Research Ethics Committee of the University of KwaZulu-Natal (Westville Campus: HSS/0221/07D). High ethical standards were followed in all aspects of the research process. Data collection ensued once ethical clearance was obtained from the researchers' affiliated academic institution. All possible participants were provided with an overview of the study before inviting them to voluntarily participate. Participants were assured anonymity and confidentiality of their responses and were informed that they could withdraw from the study at any stage, should they feel it necessary to do so. All participants signed informed consent forms and agreed to their interviews being recorded. On request, participants were provided with a copy of their interview transcripts.

\section{Results}

\section{Themes and subthemes}

Two key themes emerged from the participants' accounts during the interviews. These revealed that the consequences of misfit are in two major areas: (1) causing negative reactions in individual employees and (2) producing organisationally directed detrimental outcomes. Several subthemes were falling under the rubric of each theme.

\section{Theme 1: Causing negative reactions in individual employees}

Subtheme 1.1: Provoking and sustaining undesirable attitudinal responses: Participants' attitudes were negatively affected because of the onset of their misfit. For example, a large number of participants' (73\%) self-confidence declined. This was articulately relayed by Participant 2 and Participant 39:

'It did not take long for my morale to drop and my self-confidence levels to decline. That's how powerful the condition of misfit is ... No matter how strong a character we are, we all have an element of self-doubt, when we discover we don't fit in'. (P2, female, 33 years old, marketing and sales)

'Being a misfit impacted negatively on my level of selfconfidence. I began to believe that I did not have the ability to do my job. My manager and co-workers got a sense of this and thus started to push me around by giving me menial tasks, like filing'. (P39, female, 27 years old, retailing)

Participants $(60 \%)$ further lamented that they became demotivated in their organisations. For example, Participant 6 said:

'I experienced demotivation recently in my current organisation. Because I did not fit in, I felt that I was not really valued, and as a consequence, I was not prepared to put in an effort at work. I had a feeling that it was not necessary, as I did not have a long-term future with the company. Demotivation really caused me to resent my job, my co-workers and manager'. (P6, female, 27 years old, supply chain and logistics)

Subtheme 1.2: Triggering and intensifying adverse psychological reactions: Participants indicated that their misfit negatively affected them psychologically. Depression was a condition experienced by a cohort of participants (55\%). For example, Participant 2 and Participant 8 stated that:

'... what I also noticed is that it affects you psychosomatically because you end up a few times on tranquilisers and I mean I know this for a fact ... and a lot of the time on antidepressants just to be able to cope ... A few years ago, I was treated for depression because I was then unhappy in my workplace as a result of my misfit'. (P2, female, 33 years old, marketing and sales)

'Depression got hold of me at the very point when I discovered that I did not fit in with my job and people in my workplace. That was a dark period ... I then decided to visit a clinical psychologist for the first time in my life'. (P8, male, 22 years old, retailing)

Participants (48\%) also described having experienced anxiety and resentment. Participant 17 gave a poignant account of his experience:

'... I became anxious and then angry with myself and the organisation. I developed a mentality of "I want to show you a point" ... This became self-destructive as further emotions were stimulated in me such as resentment...'. (P17, female, 26 years old, higher education) 
Misfit led to a number of the participants (63\%), reporting that their stress levels had increased substantially. Participant 9 and Participant 22 commented:

'As a result of being a misfit, I could feel that I was not competent enough for the position. This had the effect of radically increasing my stress levels. I could not sleep at night and had neck spasms'. (P9, female, 23 years old, marketing and sales)

'My work and personal relationships went downhill as a result of my misfit ... I was constantly stressed out. I was regretting taking on this job...'. (P22, female, 35 years old, marketing and sales)

A few participants $(10 \%)$ considered suicide. One of the most harrowing responses came from Participant 4 who had contemplated ending his life:

'Misfit had an extreme impact on me personally to such an extent that I considered taking a drug overdose. I was on the verge of committing suicide'. (P4, male, 46 years old, financial services)

Subtheme 1.3: Initiating and exacerbating harmful physiological reactions: Participants (33\%) complained that their health was severely affected as a result of their misfit. They used emotional language when describing it as a dreadful experience and devastating condition to be burdened with. Their medical conditions incrementally deteriorated with time and in extreme cases led to hospitalisation. Participant 12 and Participant 21 related their experiences:

'I became very, very ill ... I started getting ulcers, my blood pressure went up to over 200, my sinuses started troubling, I got these severe migraines that I could not explain ... I felt like I was going to collapse and die. I really needed to take care of myself...'. (P12, male, 48 years old, higher education)

'In my case, I was pushed into a certain job ... I then became a misfit and this exacerbated my heart condition and diabetes. I could not cope ... My medical condition got so bad that I had to be hospitalised'. (P21, female, 59 years old, supply chain and logistics)

\section{Theme 2: Producing organisationally directed detrimental outcomes}

Subtheme 2.1: Contributing to a toxic organisational culture: Participants $(70 \%)$ stated that their covert and overt actions or behaviours had a deleterious effect in terms of contributing to a harmful culture, which spread rapidly and created mayhem throughout many of their organisations. Participant 13 and Participant 27 were forthright in their responses:

'When I worked for a major retailer, there were quite a few misfits at the corporate office and we would actively spread our negativity throughout the organisation on a daily basis. In fact, it took only a few months for the entire corporate office, to be contaminated with this negativity'. (P13, female, 39 years old, retailing)

'Employee misfits can really change a normal organisational environment into a toxic one. We misfits encouraged political behaviour and animosity among co-workers. In many instances, we were so destructive that we actually forced people to turn against each other. The organisational climate changed for the worst $\ldots$ backstabbing and unethical behaviour become rampant'. (P27, female, 38 years old, higher education)

Subtheme 2.2: Destroying team dynamics: A group of participants $(30 \%)$ stated that their team environments suffered immeasurably. Tension, conflict, political behaviour and other adversarial reactions became the norm, which drastically impacted on the performance of their teams. Participant 7 and Participant 9 were candid in their views:

'Other members of the team tried to cover up for us misfits by soaking up the additional pressure ... This affected the morale of the team in a bad way ... we as misfits were inclined to work in silos, which proved disastrous for the team'. (P7, female, 29 years old, supply chain and logistics)

'Teamwork suffered with us misfits in the team ... co-workers were saddled with the additional work as a result of us misfits not performing. This created animosity, conflict and interaction was more personal and vindictive...'. (P9, female, 23 years old, marketing and sales)

Subtheme 2.3: Negatively affecting company reputation and image: According to a number of participants (60\%), a significant consequence of misfit was a decline in the reputation and image of organisations in the marketplace and communities. This deterioration could be attributable to the collective inaction and destructive behaviour of misfits. This sentiment was incisively and honestly expressed by Participant 26 in his response:

'... I did not treat clients in the appropriate manner, as I was very disgruntled about my misfit predicament ... I would not follow up on queries and clients would get agitated about this. These clients, by word-of-mouth, spread negative views about the organisation ... news spreads quite fast ... it tarnished the company's image and the negative publicity could have brought the company down'. (P26, male, 40 years old, financial services)

Subtheme 2.4: Unfavourably impacting on absenteeism, employee turnover, productivity or performance and service levels: Participants (55\%) often resorted to absenteeism as a form of escapism or vindictiveness when dealing with their misfit. Participant 20 and Participant 35 were open about their experiences:

'As a misfit, I came up with every reason possible not to go to work and that was a major problem. Once I had used up all my leave, I took further time off by coming late to work or leaving early'. (P20, female, 25 years old, pharmaceutical)

'I engaged in deviant behaviour, like, unauthorised time off, extended sick leave, etc., when I felt I didn't fit in'. (P35, male, 26 years old, financial services)

Employee turnover was also cited by participants (50\%) as a noteworthy organisational consequence of misfit. This would have added to the cost burden of their organisations in terms of additional recruitment, training and development costs for new employees. Participant 5 stated:

'... employee turnover, as a result of my misfit and others, would have significantly added to our company expenses. 
TABLE 1: Themes and subthemes.

\begin{tabular}{ll}
\hline Themes & Subthemes \\
\hline $\begin{array}{l}\text { Causing negative reactions } \\
\text { in individual employees }\end{array}$ & $\begin{array}{l}\text { Provoking and sustaining undesirable } \\
\text { attitudinal responses } \\
\text { Triggering and intensifying adverse } \\
\text { psychological reactions } \\
\text { Initiating and exacerbating harmful } \\
\text { physiological reactions }\end{array}$ \\
$\begin{array}{ll}\text { Producing organisationally directed } \\
\text { detrimental outcomes }\end{array}$ & $\begin{array}{l}\text { Contributing to a toxic organisational culture } \\
\text { Destroying team dynamics } \\
\text { Negatively affecting company reputation and } \\
\text { image } \\
\text { Unfavourably impacting on absenteeism, } \\
\text { employee turnover, productivity or } \\
\text { performance and service levels }\end{array}$ \\
&
\end{tabular}

In addition to advertising and recruitment costs, there may have been further expenses in terms of relocation and induction for replacement staff'. (P5, female, 38 years old, higher education)

The cumulative impact of employee misfits could be seen in the concomitant decrease in organisational performance. This sentiment was expressed by a number of participants (72\%). Participant 2, Participant 7 and Participant 19 stated:

'Client service levels will drop. For example, as a misfit I lost interest in my job. My lack of interest spilled over into the way I interacted with customers either by email, telephone or face-to-face ... I could easily have been identified a misfit by my body language, tone of voice and choice of words'. (P2, female, 33 years old, marketing and sales)

'I believe I am a misfit and currently very unhappy ... I am reluctant to do my work properly and as a result, my performance has dropped drastically. I have been told by management that my declining performance has impacted negatively on the overall organisational productivity'. (P7, female, 29 years old, supply chain and logistics)

'As a misfit I have performed below the benchmark standards set by the organisation. If all the misfits behave the same, this could result in the company not meeting its long-term strategic goals for growth and profitability...'. (P19, female, 56 years old, pharmaceutical)

Table 1 provides a summary of the various themes and subthemes that emerged from the interview data.

\section{Discussion}

\section{Outline of the results}

The results show that misfit had an impact in two major areas: (1) causing negative reactions in individual employees undergoing this experience, and, in turn, these employees, by their attitudes, actions and behaviours, were enablers of (2) producing organisationally directed detrimental outcomes.

\section{Causing negative reactions in individual employees}

Misfit provoked and sustained a number of negative attitudinal responses in the participants who reported that their morale and self-confidence declined. They subsequently became demotivated, not prepared to put in an effort at work and questioned their long-term future with their organisations. Deng et al. (2016) recommended the theory of ego-depletion (Baumeister \& Vohs, 2007) as a useful explanatory mechanism for understanding the negative effects of value incongruence. Ego depletion theory, in this context, suggests that individuals whose values are incongruent with their organisations are caught in a dilemma and under conflict and strain concerning whether to adhere to their own values or that of their organisations when executing their work tasks and functions. The values of individuals, however, are inherently stable and robust, and this creates a situation where individuals' will have to engage in 'effortful selfregulation' to deal with this challenge (Deng et al., 2016, p. 435). This arduous self-regulation results in energy reduction or ego depletion, and this has a negative impact on individuals' attitudes and behaviours. Similarly, as highlighted earlier, the COR theory (Hobfoll, 1989) when applied to misfit may suggest that individuals will experience a loss of resources when trying to meet the demands of their workplaces. This eventually may lead to a resource loss spiral, which is accompanied by a range of negative attitudes and behaviours (Wheeler et al., 2013).

Misfit also initiated and exacerbated harmful and adverse psychological and physiological reactions in individuals. The PE fit approach to stress is useful in our understanding of stress in organisations. Edwards and Cooper (1990) contend that stress is a mismatch or a lack of similarity between the characteristics of the individual and the environment. This lack of correspondence or misfit is posited to create 'deleterious psychological, physiological, and behavioural outcomes which eventually result in increased morbidity and mortality' (Edwards \& Cooper, 1990, p. 293). These principles and logic suggest that misfit could increase the levels of stress, depression, burnout and ill-health amongst individuals as experienced in this study. Le Fevre, Matheny and Kolt (2003) made several noteworthy remarks when exploring the concepts of stress, distress and eustress in their theoretical paper. They refer to PE fit theory to support their contention that a lack of fit or misfit may lead to physiological or psychological stress or both. Past empirical research has also demonstrated support for value incongruence's effect on increasing stress, strain and burnout (e.g. Bocchino et al., 2003; Siegall \& McDonald, 2004). Participants, in this study, suffered immensely with severe medical conditions, and in some cases this led to hospitalisation. Depression, anxiety and stress were also perennially experienced by participants. They struggled to cope and the darker side of misfit was exposed when Participant 4 had considered a drug overdose and was on the brink of committing suicide because of the agonising and unrelenting experience.

The results thus reveal that misfit was extremely distressing and harsh to individuals experiencing this phenomenon it alluded to a more intense and incapacitating experience than what had been demonstrated in the quantitative research that has dominated the literature hitherto. 


\section{Producing organisationally directed detrimental outcomes}

Employee misfits, by their attitudes, actions and behaviours, were enablers of a range of organisationally directed detrimental outcomes. These results suggest a much more pervasive impact of misfit that extends beyond the individual and to the broader context of the organisation. There is a dearth of research that has examined the consequences of misfit from this angle. Employees who misfit became toxic and this, in turn, contributed to a toxic organisational culture. Bitting (2006) noted that toxic employees can contaminate the organisational climate and this toxicity is pernicious and could force other employees to an inauspicious position of low morale and job performance. In describing a toxic organisational culture, West (2020) refers to its negative impact in incapacitating its employees and discontinuing creativity and inhibiting the passion for customer service.

Employee misfits, who were members of teams, influenced its dynamics in a destructive way - incidents of nonperformance by misfits escalated as well as tension and conflict. Tentative support for this result could be found in the empirical study of Hobman and Bordia (2006) who showed that value dissimilarity was associated with increased relationship conflict in a sample MBA student teams. Vogel and Feldman (2009) noted that achieving person-group fit with group members has been associated with an increased quality of work relationships, and this could have a positive impact on group productivity. In contrast, misfit with team members could be accompanied by a breakdown in work relationships resulting in group disunity, low morale and performance.

Employee misfits, by their actions and behaviours, affected their organisations' reputation and image in the marketplace and amongst various stakeholders. Corporate reputation is a multifaceted concept and difficult to define (Walker, 2010); however, one of the key elements in achieving a good reputation is the behaviour of its employees. A respectable reputation is one of an organisation's most valued intangible resources, which could provide it with a sustainable competitive advantage in the marketplace (Pires \& Trez, 2018).

Employee misfits had an unfavourable impact on absenteeism, employee turnover, job performance and service levels to clients or customers. These negative behaviours proved costly to organisations. Participants spoke openly about taking extended sick leave, unauthorised time off and engaging in other deviant behaviours as a form of maliciousness directed at their organisations. Previous empirical research found that demographic- and personality-based dissimilarities were related to deviant behaviour (Liao, Joshi, \& Chuang, 2004), and employees' perceptions of their over qualifications have links to CWB (Liu et al., 2015). Participants admitted that their work performance declined considerably because of the onset of their misfit and this would have had an unfavourable impact on their organisations' overall productivity. The exact extent of this organisational impact and how it could be determined could not be established in a study of this nature. Past quantitative studies examining the relationship between misfit and job performance focussed on individual-related performance (e.g. Fuller \& Kaplan, 2004; Trautmann et al., 2011) and fell short of determining its overall organisational impact.

Participants also described how their level of service to clients declined because of their misfit. There is a paucity of research that examined the relationship between misfit and job performance in the context of client service. Although participants suggested that employee turnover as a consequence of misfit would add to the cost burden of organisations in terms of increased recruitment, training and development expenses for replacement employees, they did not indicate whether they intended to leave their organisations in the near future. This reluctance to exit their organisations and find another job could perhaps be attributable to the challenges of finding work in a country such as South Africa where unemployment is consistently high. In the fourth quarter of 2019, it was reported that South Africa's unemployment stood at 29.1\% of the economically active population (Statistics SA, 2020). Wheeler et al. (2007) showed that perceived job mobility is an important moderating variable in the misfit and employee turnover relationship. However, there is a lack of research that sheds light on how the slow economic growth and the high unemployment rate in South Africa influence employees to remain in their jobs despite experiencing high levels of misfit and the deleterious consequences associated with it.

\section{Practical implications}

This study sought to illuminate and provide an in-depth understanding of the consequences of misfit as experienced by individuals in the workplace. The results have implications for practice in the following ways. Firstly, the results which reveal the consequences of misfit in a negative, harmful and debilitating light could raise awareness amongst managers in organisations. This heightened awareness might encourage these managers to develop strategies and implement systems to measure and benchmark these consequences. Secondly, this newfound insight into the consequences of misfit may well lead managers to develop strategies to manage misfit more effectively and to support those employees who are experiencing this condition. Due consideration should be given to embracing fit as one of the key criteria in the recruitment and selection of new employees. A number of other strategies such as introducing employee wellness programmes could be adopted to deal with the psychological and physiological effects of misfit. Management could also subject misfits to further training, job rotation or transfer to other departments or branches 
where they could fit in. Thirdly, the results could raise awareness amongst existing and nascent employee misfits to seek help to address their condition before they metamorphose into full-blown misfits. Employees who misfit could be encouraged to disclose their condition and proactively take steps to cope, alleviate or eliminate it before opting to exit their organisations.

\section{Limitations and recommendations}

This study is not devoid of limitations. Firstly, we used a single method to collect data, namely face-to-face, semistructured, in-depth interviews. Although this proved beneficial in drawing rich data, there were shortcomings such as researcher bias, which could have influenced the findings or omitted critical information about the consequences of misfit. Future research could investigate this angle of misfit by using other qualitative data collection methods such as focus groups and storytelling. Perhaps, these methods would unearth new data that could significantly broaden our knowledge base.

Secondly, the coding and generation of themes or subthemes were undertaken by the researchers in the way they understood it to be and corroborated by an experienced individual in qualitative research. A different group of researchers might have coded this data differently resulting in a variation in the themes or subthemes. Future research should improve on the validation of the coding and resulting themes or subthemes by ensuring that more independent checking is performed by researchers experienced in qualitative data analysis.

Thirdly, this study revealed that the effects of misfit are much more penetrating and extreme than what had been shown in previous quantitative research. The 'darker side' of misfit was exposed when a participant indicated that his misfit was so intense that he contemplated committing suicide. Future research should explore this 'dark' and devastating side of misfit further to gain an understanding of how misfit influences individuals to consider ending their lives.

Fourthly, participants indicated that they were reluctant to leave their organisations despite their harrowing experiences with misfit. This inclination to remain in their organisations could be attributable to the perennially high unemployment rate in South Africa where finding new job opportunities could pose a severe challenge. Future research should investigate whether and how the high unemployment rate influences employee misfits to remain in their organisations.

Finally, because of the nature of this qualitative study, the sample size and approach used, the findings lack generalisability to the broader population of employee misfits. Future research could investigate misfit by using quantitative approaches with large sample sizes. However, cognisance should be taken regarding the development and validation of a misfit-measuring instrument that seeks to capture the true essence of this dynamic construct in these quantitative studies.

\section{Conclusion}

This study answered the call for more research into misfit to increase our understanding of this highly complex and elusive construct. The main objective of this study was to explore the consequences of misfit from the perspectives of individuals' experiences in the workplace by using a qualitative, constructivist grounded theory approach. The results revealed that the consequences of misfit were in two main areas: (1) causing negative reactions in individual employees undergoing this experience, and in turn, these employees, by their attitudes and behaviours, were enablers of (2) producing organisationally directed detrimental outcomes. This study showed that the effects of misfit are much more penetrating, extreme and pervasive than what had been shown in previous quantitative research. Misfit is a highly contested and nebulous construct and that we have only 'skimmed the surface' in uncovering its consequences in the workplace. Perhaps, this research will serve as a catalyst for more scholarly inquiry into this subject area.

\section{Acknowledgements Competing interests}

The authors declare that they have no financial or personal relationships that may have inappropriately influenced them in writing this article.

\section{Authors' contributions}

All authors have contributed equally to this work.

\section{Funding information}

This research received no specific grant from any funding agency in the public, commercial or not-for-profit sectors.

\section{Data availability statement}

The authors confirm that the data supporting the findings of this study are available within the article.

\section{Disclaimer}

The views and opinions expressed in this article are those of the authors and do not necessarily reflect the official policy or position of any affiliated agency of the authors.

\section{References}

Andela, M., \& Van der Doef, M. (2019). A comprehensive assessment of the person-environment fit dimensions and their relationship with work-related outcomes. Journal of Career Development, 46(5), 567-582. https://doi. org/10.1177/0894845318789512

Bao, Y., Vedina, R., Moodie, S., \& Dolan, S. (2013). The relationship between value incongruence and individual and organizational well-being outcomes: An exploratory study among Catalan nurses. Journal of Advanced Nursing, 69(3), 631-641. https://doi.org/10.1111/j.1365-2648.2012.06045.x 
Barrick, M., \& Parks-Leduc, L. (2019). Selection for fit. Annual Review of Organizational Psychology and Organizational Behavior, 6(1), 171-193. https://doi.org/10.1146/ annurev-orgpsych-012218-015028

Baumeister, R.F., \& Vohs, K.D. (2007). Self-regulation, ego depletion, and motivation Social and Personality Psychology Compass, 1(1), 115-128. https://doi. $\mathrm{org} / 10.1111 / \mathrm{j} .1751-9004.2007 .00001 . x$

Bermiss, Y.S., \& McDonald, R. (2018). Ideological misfit? Political affiliation and employee departure in the private-equity industry. Academy of Management Journal, 61(6), 2182-2209. https://doi.org/10.5465/amj.2016.0817

Billsberry, J. (2008, November 19-21). Broad sketches on misfit as an organisational psychopathology. Paper presented at the 2nd Global e-Conference on Fit. Retrieved from https://www.conference.fit/images/2008.arch/Thur02.pdf

Billsberry, J., Ambrosini, V., Marsh, P., Moss-Jones, J., \& Van Meurs, N. (2005, September 13-15). Towards a composite map of organisational personenvironment fit. Paper presented at the British Academy of Management (BAM) Annual Conference, Oxford University, Oxford, UK. Retrieved from https://www. academia.edu/27938223/Towards_a_composite_map_of_organisational person-environment_fit1

Bitting, R.K. (2006). Toxic employees. Retrieved from https://www.robertbitting.com/ assets/pdf/Toxic-Employees-in-the-Work-Place.pdf

Bocchino, C.C., Hartman, B.W., \& Foley, P.F. (2003). The relationship between person organization congruence, perceived violations of the psychological contract, and occupational stress symptoms. Consulting Psychology Journal: Practice and Research, 55(4), 203-214. https://doi.org/10.1037/1061-4087.55.4.203

Bouckenooghe, D., Buelens, M., Fontaine, J., \& Vanderheyden, K. (2005). The prediction of stress by values and value conflict. The Journal of Psychology: Interdisciplinary and Applied, 139(4), 369-384. https://doi.org/10.3200/ JRLP.139.4.369-384

Broom, A., \& Willis, E. (2007). Competing paradigms in health research. In M. Saks \& J. Allsop (Eds.), Researching health: Qualitative, quantitative and mixed methods (pp. 16-31). London: Sage Publications.

Bryant, A., \& Charmaz, K. (2007). Grounded theory research: Methods and practices. In A. Bryant \& K. Charmaz (Eds.), The Sage handbook of grounded theory (pp. 1-28). Thousand Oaks, CA: Sage Publications.

Charmaz, K. (2006). Constructing grounded theory: A practical guide through qualitative analysis. London: Sage Publications.

Cools, E., Van den Broeck, H., \& Bouckenooghe, D. (2009). Cognitive styles and personenvironment fit: Investigating the consequences of cognitive (mis)fit. European Journal of Work and Organizational Psychology, 18(2), 167-198. https://doi. org/10.1080/13594320802295540

Cooper-Thomas, H.D., \& Wright, S. (2013). Person-environment misfit: The neglected role of social context. Journal of Managerial Psychology, 28(1), 21-37. https://doi. org/10.1108/02683941311298841

Creswell, J.W., \& Poth, C.N. (2018). Qualitative inquiry and research design: Choosing among five approaches (4th ed.). Thousand Oaks, CA: Sage Publications.

David, E.M., Avery, D.R., Witt, L.A., Tonidandel, S., McKay, P.F., Brown, L., \& Crepeau, L. (2019). Helping misfits to commit: How justice climate attenuates the effects of personality dissimilarity on organizational commitment. Journal of Business and Psychology, 34(4), 503-517. https://doi.org/10.1007/s10869-018-9556-7

De Cooman, R., Mol, S.T., Billsberry, J., Boon, C., \& Den Hartog, D.N. (2019). Epilogue: Frontiers in person-environment fit research. European Journal of Work and Organizational Psychology, 28(5), 646-652. https://doi.org/10.1080/135943 2X.2019.1630480

Deng, H., Wu, C.-H., Leung, K., \& Guan, Y. (2016). Depletion from self-regulation: $A$ resource-based account of the effect of value incongruence. Personne Psychology, 69(2), 431-465. https://doi.org/10.1111/peps.12107

Doblhofer, D.S., Hauser, A., Kuonath, A., Haas, K., Agthe, M., \& Frey, D. (2019). Make the best out of the bad: Coping with value incongruence through displaying facades of conformity, positive reframing, and self-disclosure. European Journal of Work and Organizational Psychology, 28(5), 572-593. https://doi.org/10.1080/13 59432X.2019.1567579

Edwards, J.R. (2008). Person-environment fit in organizations: An assessment of theoretical progress. Academy of Management Annals, 2(1), 167-230. https:// doi.org/10.1080/19416520802211503

Edwards, J.R., \& Cooper, C.L. (1990). Person-environment fit approach to stress: Recurring problems and some suggested solutions. Journal of Organizational Behavior, 11(4), 293-307. https://doi.org/10.1002/job.4030110405

Follmer, E.H., Talbot, D.L., Kristof-Brown, A.L., Astrove, S.L., \& Billsberry, J. (2018). Resolution, relief, and resignation: A qualitative study of responses to misfit at work. Academy of Management Journal, 61(2), 440-465. https://doi.org/10.5465/ amj.2014.0566

Fuller, L.R., \& Kaplan, S.E. (2004). A note about the effect of auditor cognitive style on task performance. Behavioral Research in Accounting, 16(1), 131-143. https:// doi.org/10.2308/bria.2014.16.1.131

Guba, E.G., \& Lincoln, Y.S. (1989). Fourth generation evaluation. Newbury Park, CA: Sage Publications.

Harrison, D.A. (2007). Pitching fits in applied psychological research: Making fit methods fit theory. In C. Ostroff \& T.A. Judge (Eds.), Perspectives on organizational fit (pp. 389-416). New York, NY: Lawrence Erlbaum Associates.

Hewlin, P.F., Dumas, T.L., \& Burnett, M.F. (2017). To thine own self be true? Facades of conformity, value incongruence, and the moderating impact of leader integrity. Academy of Management Journal, 60(1), 178-199. https://doi.org/10.5465/ amj.2013.0404
Hobfoll, S.E. (1989). Conservation of resources: A new attempt at conceptualizing stress. American Psychologist, 44(3), 513-524. https://doi.org/10.1037/0003066X.44.3.513

Hobman, E.V., \& Bordia, P. (2006). The role of team identification in dissimilarityconflict relationship. Group Processes \& Intergroup Relations, 9(4), 483-507. https://doi.org/10.1177/1368430206067559

Hollyoak, B.M. (2016). Towards an understanding of the psychological construct of misfit: A grounded theory study (Unpublished PhD thesis). Coventry University, Coventry. Retrieved from https://ethos.bl.uk/OrderDetails.do?uin=uk.bl. ethos.783214

Hollyoak, B.M., Talbot, D., Pyper, N., \& Billsberry, J. (2017, September 5-7). Vocalising the experience of misfit: A netnographic study. Paper presented at the British Academy of Management (BAM), Warwick Business School, University of Warwick, Warwick. Retrieved from https://bam.ac.uk/sites/bam.ac.uk/files/ BAM2017_Digital_pdf.pdf

Jansen, K.J., \& Kristof-Brown, A.L. (2005). Matching the beat of a different drummer Examining the impact of pacing congruence. Organizational Behavior and Human Decision Processes, 97(2), 93-105. https://doi.org/10.1016/j. obhdp.2005.03.005

Kristof-Brown, A.L., \& Guay, R.P. (2011). Person-environment fit. In S. Zedeck (Ed.), APA handbook of industrial and organizational psychology, Vol. 3. Maintaining, expanding, and contracting the organization (pp. 3-50). Washington, DC: American Psychological Association.

Kristof-Brown, A.L., Zimmerman, R.D., \& Johnson, E.C. (2005). Consequences of individuals fit at work: A meta-analysis of person-job, person-organization, person-group, and person-supervisor fit. Personnel Psychology, 58(2), 281-342. https://doi.org/10.1111/j.1744-6570.2005.00672.x

Le Fevre, M., Matheny, J., \& Kolt, G.S. (2003). Eustress, distress, and interpretation in occupational stress. Journal of Managerial Psychology, 18(7), 726-744. https:// doi.org/10.1108/02683940310502412

Liao, H., Joshi, A., \& Chuang, A. (2004). Sticking out like a sore thumb: Employee dissimilarity and deviance at work. Personnel Psychology, 57(4), 969-1000. https://doi.org/10.1111/j.1744-6570.2004.00012.x

Lincoln, Y.S., \& Guba, E.Y. (1985). Naturalistic inquiry. Thousand Oaks, CA: Sage Publishing.

Liu, S., Luksyte, A., Zhou, L., Shi, J., \& Wang, M. (2015). Overqualification and counterproductive work behaviors: Examining a moderated mediation model. Journa of Organizational Behavior, 36(2), 250-271. https://doi.org/10.1002/job.1979

McGhee, G., Marland, G.R., \& Atkinson, J. (2007). Grounded theory research: Literature reviewing and reflexivity. Journal of Advanced Nursing, 60(3), 334-342. https://doi.org/10.1111/j.1365-2648.2007.04436.x

Mills, J., Bonner, A., \& Francis, K. (2006). The development of constructivist grounded theory. International Journal of Qualitative Methods, 5(1), 25-35. https://doi. org/10.1177/160940690600500103

Neuman, W.L. (2014). Social research methods: Qualitative and quantitative approaches (7th ed.). Essex: Pearson Education Ltd.

Oh, I., Guay, R.P., Kim, K., Harold, C.M., Lee, J., Heo, C., \& Shin, K. (2014). Fit happens globally: A meta-analytic comparison of the relationships of person-environment fit dimensions with work attitudes and performance across East Asia, Europe, and North America. Personnel Psychology, 67(1), 99-152. https://doi.org/10.1111/ peps.12026

Park, S., Oh, S., \& Lee, Y. (2018). The relationships between person-organization value fit and employee attitudes in a Korean government sector. The International Journal of Human Resource Management, 1-26. https://doi.org/10.1080/095851 92.2018.1431954

Pires, V., \& Trez, G. (2018). Corporate reputation: A discussion on construct definition and measurement and its relation to performance. Revista de Gestão, 25(1), 47-64. https://doi.org/10.1108/REGE-11-2017-005

Schindler, P.S. (2019). Business research methods (13th ed.). New York, NY: McGraw-Hill.

Schneider, B. (1987). The people make the place. Personnel Psychology, 40(3), 437-453. https://doi.org/10.1111/j.1744-6570.1987.tb00609.x

Shaw, J.D., \& Gupta, N. (2004). Job complexity, performance and well-being: When does supplies-values fit matter? Personnel Psychology, 57(4), 847-879. https://doi.org/10.1111/j.1744-6570.2004.00008.x

Siegall, M., \& McDonald, T. (2004). Person-organization value congruence, burnout and diversion of resources. Personnel Review, 33(3), 291-301. https://doi. org $/ 10.1108 / 00483480410528832$

Silverthorne, C. (2004). The impact of organizational culture and person-organization fit on organizational commitment and job satisfaction in Taiwan. Leadership \& Organization Development Journal, 25(7), 592-599. https://doi.org/10. 1108/01437730410561477

Statistics SA. (2020). Quarterly labour force survey (QLFS) - Q4: 2019. Retrieved from http://www.statssa.gov.za/?p=12948

Talbot, D.L., \& Billsberry, J. (2007, November 19-21). Employee fit and misfit: Two ends of the same spectrum? Paper presented at the 1st Global e-Conference on Fit. Retrieved from https://www.conference.fit/images/2007arch/tue02.pdf

Talbot, D.L., \& Billsberry, J. (2010, December 8-9). Comparing and contrasting person-environment fit and misfit. Paper presented at the 4th Global e-Conference on Fit. Retrieved from https://www.conference.fit/images/2010arch/wed02.pdf

Trautmann, M., Voelcker-Rehage, C., \& Godde, B. (2011). Fit between workers' competencies and job demands as a predictor for job performance over the work career. Journal for Labour Market Research, 44(4), 339-347. https://doi. org/10.1007/s12651-011-0078-2 
Vleugels, W., Tierens, H., Billsberry, J., Verbruggen, M., \& De Cooman, R. (2019), Profiles of fit and misfit: A repeated weekly measures study of perceived value
congruence. European Journal of Work and Organizational Psychology, 28(5), 616-630. https://doi.org/10.1080/1359432X.2019.1583279

Vogel, R.M., \& Feldman, D.C. (2009). Integrating the levels of person-environment fit: The roles of vocational fit and group fit. Journal of Vocational Behavior, 75(1) 68-81. https://doi.org/10.1016/j.jvb.2009.03.007

Vogel, R.M., Rodell, J.B., \& Lynch, J.W. (2016). Engaged and productive misfits: How job crafting and leisure activity mitigate the negative effects of value incongruence. Academy of Management Journal, 59(5), 1561-1584. https://doi.org/10.5465/ amj.2014.0850

Walker, K. (2010). A systematic review of the corporate reputation literature: Definition, measurement, and theory. Corporate Reputation Review, 12(4), 357-387. https://doi.org/10.1057/crr.2009.26

West, J. (2020). The high price of a toxic company culture. Retrieved from https:// www.nbrii.com/blog/category/employee-surveys/
Wheeler, A.R., Buckley, M.R., Halbesleben, J.R.B., Brouer, R.L., \& Ferris, G.R. (2005). The elusive criterion of fit revisited: Toward an integrative theory of multidimensional fit. In J. Martocchio (Ed.), Research in personnel and human resource management (Vol. 24, pp. 265-304). Greenwich, CT: JAI Press.

Wheeler, A.R., Gallagher, V.C., Brouer, R.L., \& Sablynski, C.J. (2007). When personorganisation (mis)fit and (dis)satisfaction lead to turnover: The moderating role of perceived job mobility. Journal of Managerial Psychology, 22(2), 203-219. https:// doi..org/10.1108/02683940710726447

Wheeler, A.R., Halbesleben, J.R.B., \& Shanine, K. (2013). Exploring the middle range of person environment fit theories through a conservation of resources perspective. In A.L. Kristof-Brown \& J. Billsberry (Eds.), Organizational fit: Key issues and new directions (pp. 170-194). Oxford: Wiley Blackwell.

Yeo, A., Legard, R., Keegan, J., Ward, K., McNaughton Nichols, C., \& Lewis, J. (2014) In-depth interviews. In J. Ritchie, J. Lewis, C. McNaughton Nicholls, \& R. Ormston (Eds.), Qualitative research practice: A guide for social science students and researchers (2nd ed., pp. 177-210). London: Sage Publications. 